\title{
Near final height in Korean children referred for evaluation of short stature: clinical utility and analytical validity of height prediction methods
}

\author{
Seung Woo Jeong, MD', \\ Ja Hyang Cho, MD', \\ Hae Woon Jung, MD', \\ Kye Shik Shim, MD'
}

${ }^{1}$ Department of Pediatrics, Kyung Hee University Hospital at Gangdong, Kyung Hee University School of Medicine, Seoul, '2Department of Pediatrics, Kyung Hee University Hospital, Kyung Hee University School of Medicine, Seoul, Korea

Received: 25 August, 2017

Revised: 29 September, 2017

Accepted: 24 October, 2017

Address for correspondence:

Kye Shik Shim, MD

Department of Pediatrics, Kyung

Hee University Hospital at Gangdong, Kyung Hee University School of Medicine, 892 Dongnamro, Gangdong-gu, Seoul 05278, Korea

Tel: +82-2-440-7173

Fax: +82-2-440-7175

E-mail:64sks@khnmc.or.kr

https://orcid.org/0000-0003-49589840
Purpose: Predicted adult height (PAH) is often crucial to decision-making about treatment with human growth hormone $(\mathrm{GH})$ or gonadotropin-releasing hormone agonist in children with short stature. This study compares final adult height (FAH) with different methods used to determine PAH and assesses the clinical utility and analytical validity of height prediction for children not treated with GH.

Methods: Clinical findings were retrospectively analyzed, and the heights of 44 children (22 males and 22 females) who visited our clinic between August 2006 and June 2017 and reached near final adult height (NFAH) were evaluated. Children treated with GH were excluded. We compared measured NFAH to PAH using the Bayley-Pinneau (BP), Tanner-Whitehouse Mark 2, and Roche-Wainer-Thissen (RWT) methods.

Results: Pearson correlation between all 3 prediction methods and NFAH showed high positive correlations in males and females $(P<0.05)$. The average difference between PAH and NFAH for the BP method $(0.4 \pm 3.9 \mathrm{~cm})$ was significantly lower than those for the RWT and TW 2 methods in females ( $P=0.000$, analysis of variance). Furthermore, only PAH by the BP method in females was very close to measured $\mathrm{NFAH}$ (paired $t$-test). A Bland-Altman plot verified that $95 \%$ of the differences between the PAH and NFAH exist between limits of agreement (mean \pm 1.96 standard deviation).

Conclusion: The BP method is more useful to predict NFAH in females than other methods. Careful attention is still required when using such tools because PAH can be inaccurate. Therefore, a more accurate FAH prediction model for Korean children is needed.

Keywords: Adult height prediction method, Short stature, Final height, BayleyPinneau method

\section{Introduction}

Bone age (BA) determination and prediction of adult height is not only the oldest radiographic procedure but also the most commonly used method for such predictions.

Among prediction tools, the Bayley-Pinneau (BP) method is the most commonly used and familiar method for height prediction. First suggested in 1950 and reworked in 1959, this method is based on BA assessments according to the standards of Greulich and Pyle (GP) ${ }^{1-3}$ Following that, Tanner-Whitehouse (TW) Mark 1 method was introduced in 1975. This was revised to the TW Mark 2 in 1983 and the TW Mark 3 in 2001. ${ }^{4-6)}$ Finally, the Roche-WainerThissen (RWT) model was developed in 1975 by Roche and modified in $1993{ }^{7,8)}$ while the BoneXpert model, based on automated BoneXpert BA, was developed in 2009.')

Sperlich et al. ${ }^{10)}$ reported that the difference between the predicted adult height (PAH) using 
the BP method and observed final height was very small in boys with untreated constitutional growth delay. Maes et al. ${ }^{11)}$ stated that in short, normal children, the BP method was the most accurate for boys and the TW2 method was the most accurate for girls. Although studies comparing BA assessment using the GP and TW2 methods have been consistently reported, ${ }^{12,13)}$ studies of adult height prediction are sparse in Korea. There is only one report, from 2009, that suggested that the BP method could be the most accurate method for predicting adult height in children with precocious puberty and constitutional growth delay. $^{14)}$

Therefore, this study evaluated the clinical utility and analytical validity of height prediction testing in Korean children of normal height.

\section{Materials and methods}

This study was a retrospective investigation of 2,895 children who presented with subjective complaints of short stature to the Pediatric Endocrinology clinic of Kyung Hee University Hospital at Gangdong between August 2006 and June 2017. First, 5 children with chronic disease and 35 children with endocrine disease were excluded. Seventy-one children were excluded due to interventions with GH or gonadotropinreleasing hormone agonist, and 2,590 children were lost to follow-up. An additional 150 children, who had not achieved final adult height (FAH) at the time of study evaluation, were also excluded. Among 2,895 children, 44 children (22 males and 22 females) who had not been treated with human growth hormone $(\mathrm{GH})$ and reached near final adult height (NFAH) were included in this analysis. Of the 44 children studied, 43 were at normal or normal variants of height above -2 standard deviation score (SDS) for age and sex.

Data gathered from children's history at the time of initial assessment included age, sex, height, weight, body mass index, and parental heights. Height and weight standard deviation was determined based on the data tables of 2007 Korean Children and Adolescents Growth Standard provided by the Korea Centers for Disease Control \& Prevention. ${ }^{15)}$ Midparental height, PAH, and NFAH SDS was calculated based on the data corresponding to the age of 18.0, which is nearly close to adult height.

BA was rated by an experienced endocrinologist and a radiologist according to the GP and TW2 methods, and PAH at initial assessment was estimated using the BP, RWT, and TW Mark 2 methods. ${ }^{3,5,7)}$ The BP and RWT methods were based on GP BA and the TW Mark 2 method used TW2 BA. NFAH was measured from June 2016 to June 2017 when height velocity was less than $2 \mathrm{~cm} / \mathrm{yr}$, and NFAH was defined for patients with a $\mathrm{BA} \geq 16$ years for males and $\mathrm{BA} \geq 14$ years for females.

This research is approved from the Institutional Review Board (IRB) of Kyung Hee University Hospital at Gangdong and written informed consent was exempt from the IRB (KHNMC 2017-07-009-02).

The variables were reported as mean \pm standard deviation, and a paired $t$-test was used to compare PAH to NFAH. Oneway analysis of variance (ANOVA) was used to compare differences between PAH and NFAH in males and females separately. Pearson product-moment correlation coefficient was used to examine the relationship between PAH and NFAH. Bland-Altman analyses, proposed in 1983 as an alternative to correlation studies, were used to evaluate the agreement between the observed and PAH and to look for proportional bias. ${ }^{16,17)}$ Agreement was considered to be statistically significant when $P$-values were below 0.05. IBM SPSS Statistics ver. 20.0 (IBM Co., Armonk, NY, USA) was used for analysis of data.

\section{Results}

The basal characteristics of study subjects are listed in Table 1. Mean ages of the children were $10.6 \pm 1.2$ years in males and $9.5 \pm 1.5$ years in females. Mean heights were $137.2 \pm 6.8 \mathrm{~cm}$ $(-0.5 \pm 0.6$ SDS; range, -1.64 to 0.53 SDS $)$ in males and $130.0 \pm 8.8$ $\mathrm{cm}(-0.8 \pm 0.7$ SDS; range, -2.14 to 0.3 SDS $)$ in females. Of the 44 children, 43 had heights within normal variation above -2SDS for age and gender. Only one girl had height that was -2.14 SDS. All children showed an insignificant difference between BA and chronological age (CA) $(P=0.628)$.

The mean CAs of the 44 children who had reached NFAH were $16.2 \pm 1.2$ years in males and $15.2 \pm 1.5$ years in females. Their mean BAs by GP method were $16.5 \pm 0.6$ years in males and $15.3 \pm 1.1$ years in females and their mean BAs by TW2 method were $16.2 \pm 0.6$ years in males and $15.1 \pm 1.1$ years in females. The mean NFAHs which were actually observed were $167.8 \pm 4.7 \mathrm{~cm}(-1.0 \pm 0.9$ SDS $)$ in males and $154.9 \pm 5.1 \mathrm{~cm}$ $(-1.2 \pm 1.1$ SDS $)$ in females. The PAHs using BP, RWT and TW 2 method were $174.7 \pm 4.9 \mathrm{~cm}, 173.0 \pm 3.9 \mathrm{~cm}$ and $172.1 \pm 4.1 \mathrm{~cm}$ in males and were $155.3 \pm 3.7 \mathrm{~cm}, 161.5 \pm 3.1 \mathrm{~cm}$, and $159.7 \pm 3.5 \mathrm{~cm}$ in females (Table 2).

The correlation coefficients between the PAH and NFAH according to the different prediction methods are described in Table 3. Pearson correlation between all three prediction methods and final height showed high positive correlations in males and females $(P<0.05)$. The average differences between PAH and NFAH for the BP $(6.9 \pm 4.2 \mathrm{~cm})$, RWT $(5.2 \pm 4.1 \mathrm{~cm})$ and TW $2(4.3 \pm 3.7 \mathrm{~cm})$ methods were not significantly different

Table 1. Basal characteristics of study subjects

\begin{tabular}{lcc}
\hline Variable & Male $(\mathrm{n}=22)$ & Female $(\mathrm{n}=22)$ \\
\hline Chronologic age $(\mathrm{yr})^{*}$ & $10.6 \pm 1.2$ & $9.6 \pm 1.5$ \\
Bone age by GP method $(\mathrm{yr})$ & $10.2 \pm 1.5$ & $9.5 \pm 1.6$ \\
Height $(\mathrm{cm})$ & $137.2 \pm 6.8$ & $130.0 \pm 8.8$ \\
Height-SDS & $-0.5 \pm 0.6$ & $-0.8 \pm 0.7$ \\
Weight-SDS & $-0.4 \pm 0.9$ & $-0.7 \pm 0.8$ \\
Body mass index $\left(\mathrm{kg} / \mathrm{m}^{2}\right)$ & $17.5 \pm 3.4$ & $16.3 \pm 1.8$ \\
Midparental height & $170.6 \pm 3.0$ & $158.6 \pm 3.0$ \\
Midparental height-SDS & $-0.4 \pm 0.5$ & $-0.4 \pm 0.6$
\end{tabular}

Values are presented as mean \pm standard deviation.

GP, Greulich and Pyle; SDS, standard deviation score.

*At the time of prediction. 
in males $(P=0.157,1$-way ANOVA; Table 2$)$. The average difference between PAH and NFAH for the BP method $(0.4 \pm 3.9$ $\mathrm{cm})$ was significantly lower than those for the RWT $(6.6 \pm 3.6$ $\mathrm{cm})$ and TW2 $(4.8 \pm 4.4 \mathrm{~cm})$ methods in females $(P=0.000,1$-way ANOVA). Furthermore, only PAH by the BP method in female was very close to and no different from measured NFAH (paired $t$-test).

Thus, Bland-Altman analysis was conducted to discern agreement between NFAH and PAH using the BP method, and the difference between PAH using the BP method and NFAH

Table 2. Predicted adult height, final adult height, and their difference according to various prediction methods

\begin{tabular}{|c|c|c|}
\hline Variable & Male $(n=22)$ & Female $(n=22)$ \\
\hline \multicolumn{3}{|l|}{ PAH } \\
\hline BP method $(\mathrm{cm})$ & $174.7 \pm 4.9$ & $155.3 \pm 3.7$ \\
\hline BP method (SDS) & $0.3 \pm 0.9$ & $-1.1 \pm 0.8$ \\
\hline RWT method $(\mathrm{cm})$ & $173.0 \pm 3.9$ & $161.5 \pm 3.1$ \\
\hline RWT method (SDS) & $0.0 \pm 0.7$ & $0.2 \pm 0.6$ \\
\hline TW 2 method (cm) & $172.1 \pm 4.1$ & $159.7 \pm 3.5$ \\
\hline TW 2 method (SDS) & $-0.2 \pm 0.7$ & $-0.2 \pm 0.7$ \\
\hline \multicolumn{3}{|l|}{ NFAH } \\
\hline Chronologic age (yr) & $16.2 \pm 1.2$ & $15.2 \pm 1.5$ \\
\hline Bone age by GP method (yr) & $16.5 \pm 0.6$ & $15.3 \pm 1.1$ \\
\hline Height $(\mathrm{cm})$ & $167.8 \pm 4.7$ & $154.9 \pm 5.1$ \\
\hline Height (SDS) & $-1.0 \pm 0.9$ & $-1.2 \pm 1.1$ \\
\hline \multicolumn{3}{|l|}{ Difference between PAH and NFAH } \\
\hline PAH by BP method - NFAH (cm) & $\begin{array}{c}6.9 \pm 4.2 \\
(P=0.000)\end{array}$ & $\begin{array}{c}0.4 \pm 3.9 \\
(P=0.616)\end{array}$ \\
\hline PAH by BP method - NFAH (SDS) & $\begin{array}{c}1.2 \pm 0.8 \\
(P=0.000)\end{array}$ & $\begin{array}{c}0.1 \pm 0.8 \\
(P=0.581)\end{array}$ \\
\hline PAH by RWT method - NFAH (cm) & $\begin{array}{c}5.2 \pm 4.1 \\
(P=0.000)\end{array}$ & $\begin{array}{c}6.6 \pm 3.6 \\
(P=0.000)\end{array}$ \\
\hline PAH by RWT method - NFAH (SDS) & $\begin{array}{c}0.9 \pm 0.8 \\
(P=0.000)\end{array}$ & $\begin{array}{c}1.3 \pm 0.7 \\
(P=0.000)\end{array}$ \\
\hline PAH by TW2 method - NFAH (cm) & $\begin{array}{c}4.3 \pm 3.7 \\
(P=0.000)\end{array}$ & $\begin{array}{c}4.8 \pm 4.4 \\
(P=0.000)\end{array}$ \\
\hline PAH by TW2 method - NFAH (SDS) & $\begin{array}{c}0.8 \pm 0.7 \\
(P=0.000)\end{array}$ & $\begin{array}{c}1.0 \pm 0.9 \\
(P=0.000)\end{array}$ \\
\hline
\end{tabular}

Values are presented as mean \pm standard deviation.

$\mathrm{PAH}$, predicted adult height; $\mathrm{BP}$, Bayley-Pinneau; RWT, RocheWainer-Thissen; TW, Tanner-Whitehouse; NFAH, near final adult height; GP, Greulich and Pyle.

*Between June 2016 and June 2017. and average height in females is displayed in Fig. 1, which shows considerable agreement between PAH and NFAH. The results of Bland-Altman analysis verified that $95 \%$ of the differences between the PAH and NFAH exist between limits of agreement $($ mean $\pm 1.96 \mathrm{SD} ; 8.0$ and $-7.1 \mathrm{~cm})$.

\section{Discussion}

Several studies have been conducted to validate height prediction models. ${ }^{10,11,14,18-22)}$ Roemmich et al. ${ }^{18)}$ reported that the TW2 model gave the most accurate results, followed by the RWT and BP models. Brämswig et al. ${ }^{19)}$ reported that the RWT method gave very precise results for boys, but no method was superior in estimating adult height for girls. Ostojic ${ }^{20)}$ reported that that TW2 method was an exact method for PAH in normal-growing athletic boys, while Straetemans et al. ${ }^{21)}$ found Ranke's height prediction model for children with idiopathic GH deficiency treated with GH to be accurate.

Despite these varying results, the BP method is the most commonly used and familiar method for height prediction, and many studies including Sperlich et al. ${ }^{10)}$, Maes et al. ${ }^{11)}$, and $\mathrm{Oh}$ et al. ${ }^{14)}$ support this model as being effective for adult height prediction. Zachmann et al. ${ }^{22)}$ also preferred the BP method for

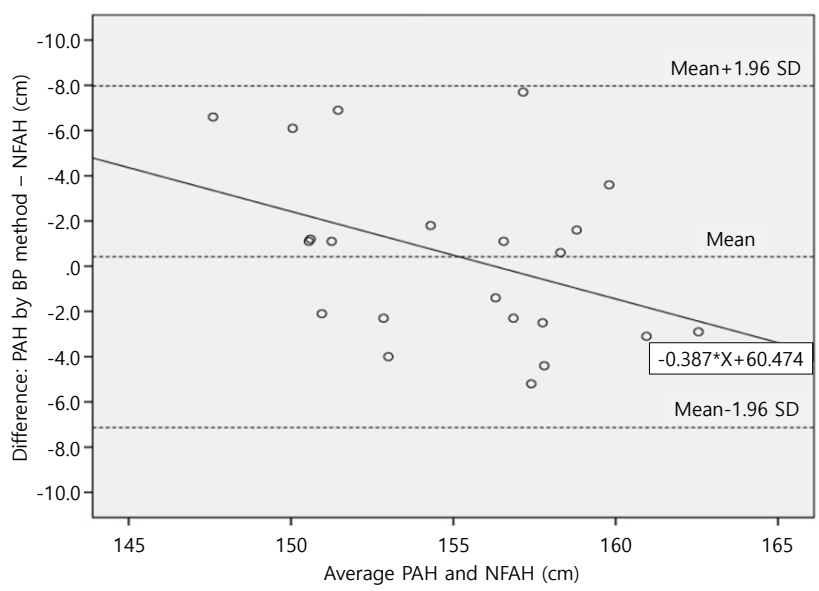

Fig. 1. Difference between predicted by BP method and NFAH in female by Bland-Altman plot. 95\% of differences between the PAH and NFAH exist between limits of agreement (mean \pm 1.96 standard deviation [SD]; 8.0 and $-7.1 \mathrm{~cm}$ ). BP, Bayley-Pinneau; NFAH, near final adult height; PAH, predicted adult height.

Table 3. Correlation between PAH and NFAH by various prediction methods

\begin{tabular}{|c|c|c|c|c|}
\hline \multirow{2}{*}{ Variable } & \multicolumn{2}{|c|}{ Male $(n=22)$} & \multicolumn{2}{|c|}{ Female $(n=22)$} \\
\hline & Pearson correlation (R) & Significance $(P)$ & Pearson correlation (R) & Significance $(P)$ \\
\hline PAH by BP method and NFAH (cm) & 0.619 & 0.002 & 0.665 & 0.001 \\
\hline PAH by BP method and NFAH (SDS) & 0.621 & 0.002 & 0.664 & 0.001 \\
\hline PAH by RWT method and NFAH (cm) & 0.548 & 0.008 & 0.726 & 0.000 \\
\hline PAH by RWT method and NFAH (SDS) & 0.544 & 0.009 & 0.723 & 0.000 \\
\hline PAH by TW2 method and NFAH (cm) & 0.650 & 0.001 & 0.536 & 0.010 \\
\hline PAH by TW2 method and NFAH (SDS) & 0.649 & 0.001 & 0.534 & 0.010 \\
\hline
\end{tabular}

PAH, predicted adult height; NFAH, near final adult height; BP, Bayley-Pinneau; SDS, standard deviation score; RWT, Roche-Wainer-Thissen; TW, TannerWhitehouse. 
children, when growth potential in relation to bone maturation was inherently reduced and could not be corrected by therapy.

In this study, all three prediction methods strongly correlated to NFAHs in males and females $(P<0.05)$. However, only PAH by the BP method in female was very close to and no different from NFAH (paired $t$-test), and the mean difference between $\mathrm{PAH}$ and NFAH for the BP method was significantly lower than those for the RWT and TW2 methods in females $(P=0.000$, 1-way ANOVA). Additionally, Bland-Altman analysis showed considerable agreement between the means of the differences between NFAH and PAH using the BP method in females. Additionally, Bland-Altman analysis showed considerable agreement between the means of the differences between NFAH and PAH using the BP method in females. Therefore, this study validated that the BP method is more useful than the other methods for predicting FAH in Korean females, which is consistent with previous studies. ${ }^{10,11,14,22)}$

The strength of this study was that it assessed three height prediction methods (i.e., BP, RWT, and TW2 methods) to compare PAHs with observed FAHs in Korean children. Oh et al. ${ }^{14)}$ compared PAHs using the BP and TW3 methods in normal children, those with precocious puberty, and those with constitutional growth delay; however, they did not compare $\mathrm{PAH}$ and measured adult height and emphasized a need for this type of comparison. Thus, the current research analyzed 44 children of almost normal or normal variants of short stature who exhibited insignificant differences between BA and CA $(P=0.628)$. Since this study group was less heterogeneous than other groups in previous studies, the results of this study can be applied to children with normal and normal variant short stature.

Despite this strength, the present study has some limitations. First, it was a retrospective study, and the size of the final study group was limited. In total, 2,895 children referred for evaluation of short stature, but 5 children with chronic disease, 35 children with endocrine disease were excluded, 71 children were treated with $\mathrm{GH}$, and 2,590 children were lost to follow-up. Although there were an additional 150 children who were not treated, they had not yet achieved FAH and so could not be included in the analysis. The mean intervals between initial and final assessment were 5.5 years for males and 5.6 years for females, which were not long enough for all children being followed up to achieve FAH. It is possible that some children's ultimate adult height results might be higher. Nonetheless, several other studies on small groups have also yielded valuable results as well as this study. ${ }^{18,23)}$ An additional limitation is that the BA rating may vary according to the examiner. Finally, we predicted height only once for each of the children, using height prediction methods at the time of the initial visit to the hospital.

In conclusion, PAH using the BP method was closer to the FAH compared to other methods for females and also significantly correlated to the FAH. Thus, the BP method may be more useful for predicting FAH than other methods for females. Although these prediction tools can be helpful in making decisions, careful attention is still required when using such methods because PAH can be inaccurate. In addition, a prospective, long-term study with more cases and a FAH prediction model for Korean children is needed.

\section{Conflict of interest}

No potential conflict of interest relevant to this article was reported.

\section{References}

1. Thodberg HH, Juul A, Lomholt J, Martin DD, Jenni OG, Caflisch J, et al. Adult height prediction models. In: Preedy VR, editor. Handbook of growth and growth monitoring in health and disease. New York: Springer, 2012:27-57.

2. BAYLEY N. Tables for predicting adult height from skeletal age and present height. J Pediatr 1946;28:49-64.

3. Bayley N, Pinneau SR. Tables for predicting adult height from skeletal age: revised for use with the Greulich-Pyle hand standards. J Pediatr 1952;40:423-41.

4. Tanner JM, Whitehouse RH, Cameron N, Marshall WA, Healy MJ, Goldstein H, et al., editors. Assessment of skeletal maturity and prediction of adult height (TW2 Method). 2nd ed. London: Academic Press, 1975.

5. Tanner JM, Landt KW, Cameron N, Carter BS, Patel J. Prediction of adult height from height and bone age in childhood. A new system of equations (TW Mark II) based on a sample including very tall and very short children. Arch Dis Child 1983;58:767-76.

6. Tanner JM, Healy MJ, Goldstein H, Cameron N. Assessment of skeletal maturity and prediction of adult height (TW3 Method). 3rd ed. London: WB Saunders, 2001.

7. Roche AF, Wainer H, Thissen D. The RWT method for the prediction of adult stature. Pediatrics 1975;56:1027-33.

8. Khamis HJ, Guo S. Improvement in the Roche-WainerThissen stature prediction model: a comparative study. Am J Hum Biol 1993;5:669-79.

9. Thodberg HH, Jenni OG, Caflisch J, Ranke MB, Martin DD. Prediction of adult height based on automated determination of bone age. J Clin Endocrinol Metab 2009;94:4868-74.

10. Sperlich M, Butenandt O, Schwarz HP. Final height and predicted height in boys with untreated constitutional growth delay. Eur J Pediatr 1995; 154:627-32.

11. Maes M, Vandeweghe M, Du Caju M, Ernould C, Bourguignon JP, Massa G. A valuable improvement of adult height prediction methods in short normal children. Horm Res 1997;48:184-90.

12. Kim SY, Yang SW. Assessment of bone age: a comparison of the Greulich Pyle method to the Tanner Whitehouse method. J Korean Soc Endocrinol 1998;13:198-204.

13. Kim SY, Oh YJ, Shin JY, Rhie YJ, Lee KH. Comparison of the Greulich-Pyle and Tanner Whitehouse (TW3) methods in bone age assessment. J Korean Soc Pediatr Endocrinol 
2008;13:50-5.

14. Oh YJ, Yu BK, Shin JY, Lee KH, Park SH, Lee KC, et al. Comparison of predicted adult heights measured by Bayley-Pinneau and Tanner-Whitehouse 3 methods in normal hildren, those with precocious puberty and with constitutional growth delay. Korean J Pediatr 2009;52:3515.

15. Korea Centers for Disease Control and Prevention, Division of Chronic Disease Surveillance, Committee for the Development of Growth Standard for Korean Children and Adolescents; Korean Pediatric Society, Committee for School Health and Public Health Statistics. 2007 Korean children and adolescents growth standard (commentary for the development of 2007 growth chart). Cheongju: Korea Centers for Disease Control and Prevention, Division of Chronic Disease Surveillance, 2007.

16. Bland JM, Altman DG. Statistical methods for assessing agreement between two methods of clinical measurement. Lancet 1986;1:307-10.

17. Giavarina D. Understanding Bland Altman analysis. Biochem Med (Zagreb) 2015;25:141-51.

18. Roemmich JN, Blizzard RM, Peddada SD, Malina RM, Roche AF, Tanner JM, et al. Longitudinal assessment of hormonal and physical alterations during normal puberty in boys. IV: predictions of adult height by the BayleyPinneau, Roche-Wainer-Thissen, and Tanner-Whitehouse methods compared. Am J Hum Biol 1997;9:371-80.

19. Brämswig JH, Fasse M, Holthoff ML, von Lengerke HJ, von Petrykowski W, Schellong G. Adult height in boys and girls with untreated short stature and constitutional delay of growth and puberty: accuracy of five different methods of height prediction. J Pediatr 1990;117:886-91.

20. Ostojic SM. Prediction of adult height by TannerWhitehouse method in young Caucasian male athletes. QJM 2013;106:341-5.

21. Straetemans S, De Schepper J, Thomas M, Verlinde F, Rooman R; BESPEED. Validation of prediction models for near adult height in children with idiopathic growth hormone deficiency treated with growth hormone: a belgian registry study. Horm Res Paediatr 2016;86:161-8.

22. Zachmann M, Sobradillo B, Frank M, Frisch H, Prader A. Bayley-Pinneau, Roche-Wainer-Thissen, and Tanner height predictions in normal children and in patients with various pathologic conditions. J Pediatr 1978;93:749-55.

23. Bueno Lozano G, Ruibal Francisco JL, Reverte Blanc F, Casado de Frías E. Accuracy of three methods of height prediction in a group of variant short stature children. An Esp Pediatr 1998;49:27-32. 